\title{
A coupled-cluster study of the enthalpy of formation of nitrogen sulfide, NS
}

\author{
Lynda R. Peebles, Paul Marshall * \\ Department of Chemistry, University of North Texas, P.O. Box 305070, Denton, TX 76203-0570, USA
}

Received 19 May 2002; in final form 17 September 2002

\begin{abstract}
The energy of NS was computed via $\operatorname{CCSD}(\mathrm{T})$ theory, together with extrapolation to the complete basis set limit and corrections for anharmonic zero-point energy, scalar and vector relativistic terms, and core-valence electron correlation. The results were employed with three working reactions to find $\Delta_{\mathrm{f}} H_{0}(\mathrm{NS})=277.3 \pm 2 \mathrm{~kJ} \mathrm{~mol}^{-1}$ and $\Delta_{\mathrm{f}} H_{298}(\mathrm{NS})=278.0 \pm 2 \mathrm{~kJ} \mathrm{~mol}^{-1}$. This thermochemistry is consistent with, but much more precise than, earlier literature values.
\end{abstract}

(c) 2002 Elsevier Science B.V. All rights reserved.

\section{Introduction}

Depending on the conditions, sulfur in flames has been found to enhance or suppress formation of nitrogen oxides [1-8]. The mechanism(s) are unknown. A species which couples nitrogen and sulfur chemistry is nitrogen sulfide, NS. This molecule has been detected in sulfur-seeded flames [9], and there have been studies of some of its reaction kinetics by Blitz and Pilling [10]. The spectroscopy of NS is known in some detail [11], but its thermochemistry is highly uncertain. O'Hare [12] used spectroscopic data to obtain $\Delta_{\mathrm{f}} H_{0}(\mathrm{NS})=$ $281 \pm 24 \mathrm{~kJ} \mathrm{~mol}^{-1}$, while two critical evaluations recommend $263 \pm 50$ and $267 \pm 105 \mathrm{~kJ} \mathrm{~mol}^{-1}$ for this quantity, respectively [13,14]. An MRD-CI

\footnotetext{
${ }^{*}$ Corresponding author. Fax: +940-565-4318.

E-mail address: marshall@unt.edu (P. Marshall).
}

computational study of a number of electronic states of NS by Lie et al. [15] implied $\Delta_{\mathrm{f}} H_{0}$ $(\mathrm{NS})=351 \mathrm{~kJ} \mathrm{~mol}^{-1}$, while more recent computational work by Nguyen et al. [16], involving calculation of $\mathrm{H}_{2} \mathrm{NSH}$ and HNS thermochemistry, yielded $282 \pm 13 \mathrm{~kJ} \mathrm{~mol}^{-1}$. The aim of the present work is to apply high accuracy coupled-cluster theory [17-19] to this problem, to establish a reliable value of $\Delta_{\mathrm{f}} H(\mathrm{NS})$ for use in flame modeling.

\section{Methodology}

Our approach is similar to the one we employed to investigate the thermochemistry of $\mathrm{H}_{2} \mathrm{~S}$ and $\mathrm{SH}$ [20]. Briefly, UCCSD(T)/RHF energies were computed with the MoLPRo program [21] using a series of correlation consistent basis sets of up to quintuple zeta quality. Geometries and energies of NS and other species were obtained with the basis 
sets aug-cc-pVDZ through aug-cc-PV5Z [22,23] and the same geometries were employed with the aug-cc-pV $(n+\mathrm{d}) \mathrm{Z}$ basis [24], where $+\mathrm{d}$ refers to the addition of inner polarization functions and $n$ ran from 2 to 5 . Core electrons were excluded from the correlation treatment. $\operatorname{CCSD}(\mathrm{T})$ core-valence correlation corrections were obtained with the ccpwCVQZ basis set of Peterson [25] employed at the geometries optimized at the $\operatorname{CCSD}(\mathrm{T}) / \mathrm{aug}$-ccpV5Z level. Vector relativistic corrections to the $\operatorname{CCSD}(\mathrm{T})$ energy were derived from experimental spin-orbit splittings [11,14]. Scalar relativistic corrections were derived from CISD/aug-cc-pV5Z calculations as the sum of mass-velocity and Darwin terms [26]. Experimental harmonic frequencies $\omega_{\mathrm{e}}$ and anharmonic terms $x_{\mathrm{e}} \omega_{\mathrm{e}}$ were used to derive zero-point vibrational energy corrections $[11,20]$. In principle, a further small contribution ' $E_{0}$ ' to the zero-point energy arises from third and fourth derivatives of the molecular potential energy [27]. We investigated this for NS at the CCSD(T)/aug-cc-pVTZ level over $\pm 0.1 \AA$ around the equilibrium geometry, and found $E_{0}$ to be less than $0.2 \mathrm{~kJ} \mathrm{~mol}^{-1}$. Depending on the force field used, $E_{0}$ lies between $0-0.25 \mathrm{~kJ} \mathrm{~mol}^{-1}$ for the $\mathrm{H}_{2} \mathrm{O}$ molecule [28]. Accordingly, we do not consider these higher-order effects further.

These data were used in three working reactions to obtain the thermochemistry of NS:

$$
\begin{aligned}
& \mathrm{NS} \rightarrow \mathrm{N}+\mathrm{S} \\
& \mathrm{NS}+\mathrm{H}_{2} \mathrm{O} \rightarrow \mathrm{NO}+\mathrm{H}_{2} \mathrm{~S} \\
& \mathrm{NS}+\mathrm{O}_{2} \rightarrow \mathrm{NO}+\mathrm{SO}
\end{aligned}
$$

The computed $0 \mathrm{~K}$ reaction enthalpies of each process were combined with experimental heats of formation of the other species to find $\Delta_{\mathrm{f}} H_{0}(\mathrm{NS})$.

\section{Results and discussion}

Table 1 summarizes the geometry of NS obtained with different basis sets. It may be seen that the error at the highest level of theory is only 0.003 A. An exponential extrapolation to the complete basis set (CBS) limit, i.e., to $n=\infty$ in the aug-cc$\mathrm{pVnZ}$ series, yields $r_{\mathrm{e}}=1.4938 \AA$ which is essen-
Table 1

Geometry of NS

\begin{tabular}{ll}
\hline Method & $\begin{array}{l}\mathrm{N}-\mathrm{S} \text { bond length, } r_{\mathrm{e}} \\
(\AA)\end{array}$ \\
\hline CCSD(T)/aug-cc-pVDZ & 1.5379 \\
CCSD(T)/aug-cc-pVTZ & 1.5129 \\
CCSD(T)/aug-cc-pVQZ & 1.5030 \\
CCSD(T)/aug-cc-pV5Z & 1.4973 \\
Experiment $^{\mathrm{a}}$ & 1.4940 \\
\hline
\end{tabular}

${ }^{a}$ Ref. [11].

tially equal to the experimental value [11]. A Morse potential fit to the CCSD(T)/aug-cc-pVTZ data for NS yields values of $\omega_{\mathrm{e}}=1204 \mathrm{~cm}^{-1}$ and $\omega_{\mathrm{e}} x_{\mathrm{e}}=6.8 \mathrm{~cm}^{-1}$, which are in good accord with the experimental values employed here of 1219 and $7.3 \mathrm{~cm}^{-1}$, respectively [11].

Table 2 shows the ab initio energies and correction terms used in the present work. Values of $\Delta_{\mathrm{f}} H_{0}$ (NS) derived via reaction (1) with different basis sets are plotted as a function of $n$ for the cc$\mathrm{pV}(n+\mathrm{d}) \mathrm{Z}$ series in Fig. 1. It may be seen that as $n \rightarrow \infty$, a limiting value is approached. We previously tested five fitting functions for extrapolation of energies to the CBS limit [20], and again for the present three working reactions we find that the best fit to the ab initio energies $E$ is obtained with the three-parameter expression $[29,30]$

$E(n)=E_{\mathrm{CBS}}+b /(n+0.5)^{4}+c /(n+0.5)^{6}$.

Good performance was also shown by a simple exponential fit and a function proposed by Wilson and Dunning for extrapolation of MP2 energies [31]. For reaction (1), the CBS limit for $\Delta_{\mathrm{f}} H_{0}$ (NS) is $276.3 \mathrm{~kJ} \mathrm{~mol}^{-1}$. There are significant changes in the bonding and electronic structure of the atoms in this dissociation reaction, which are minimized in the congeneric reactions [32] (2) and (3) which exchange atoms from same chemical group. Errors in the computed reaction enthalpies are expected to cancel to some extent, and this is borne out by Fig. 1, which shows a much weaker dependence on the size of the basis set for these two processes. The extrapolations are therefore more certain, and results are close to the limit by the time $n=4$. The CBS limits derived via reactions (2) and (3) are 276.7 and $277.8 \mathrm{~kJ} \mathrm{~mol}^{-1}$, respectively. Our best estimate of $\Delta_{\mathrm{f}} H_{0}$ (NS) is the mean of these two 


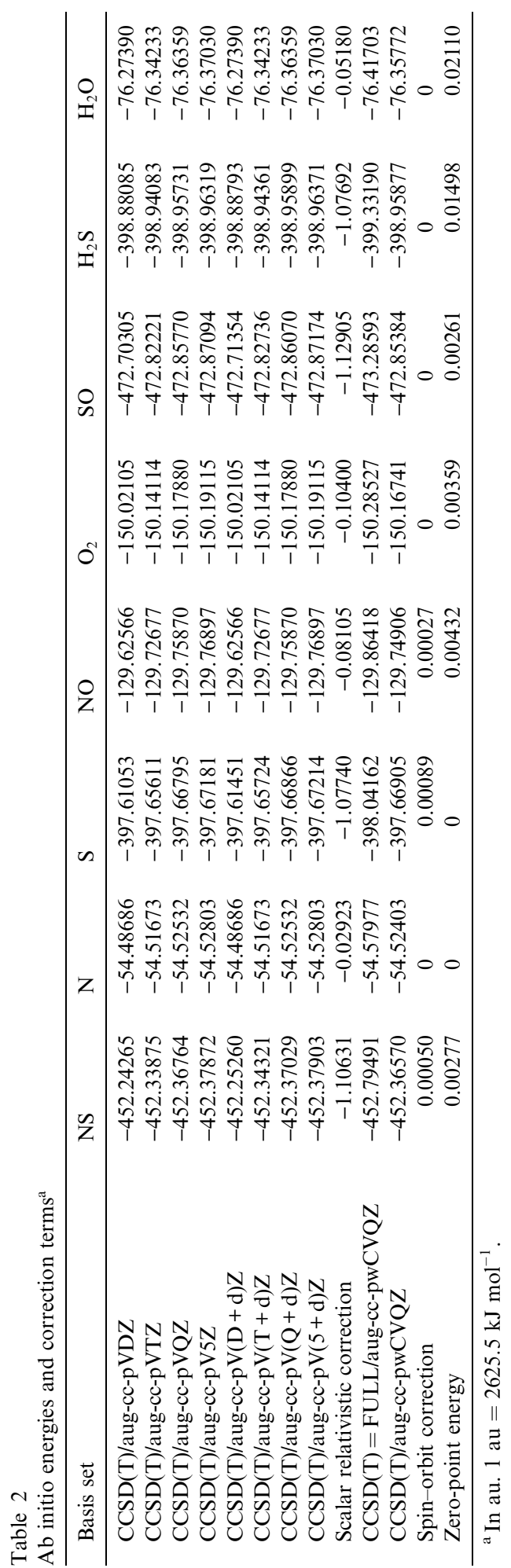

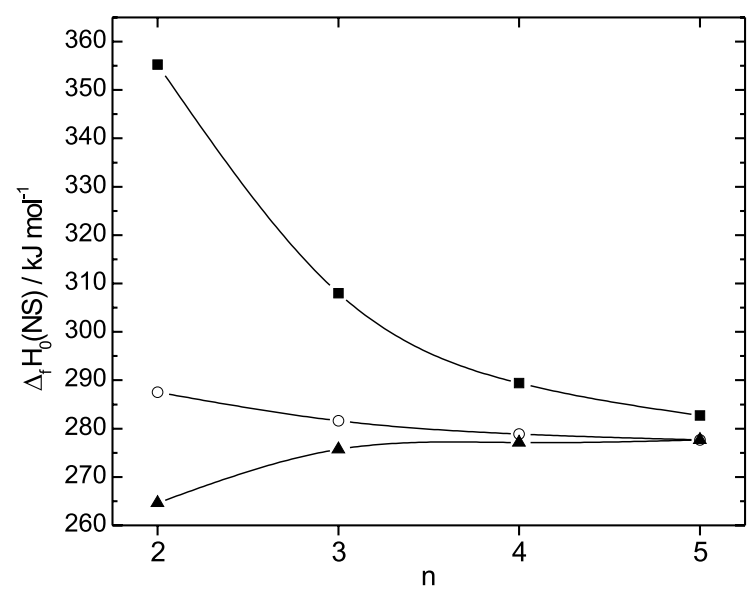

Fig. 1. Plot of the enthalpy of formation of NS derived with aug-cc-pV $(n+\mathrm{d}) \mathrm{Z}$ basis sets. Three working reactions were employed: solid squares, $\mathrm{NS} \rightarrow \mathrm{N}+\mathrm{S}$; open circles, NS+ $\mathrm{H}_{2} \mathrm{O} \rightarrow \mathrm{NO}+\mathrm{H}_{2} \mathrm{~S}$, solid triangles, $\mathrm{NS}+\mathrm{O}_{2} \rightarrow \mathrm{NO}+\mathrm{SO}$. The curves show fits (Eq. (4) in the text) which were extrapolated to the complete basis set limit.

values, $277.3 \mathrm{~kJ} \mathrm{~mol}^{-1}$. As discussed in our previous work [20], the main sources of uncertainty are the basis set extrapolations and the scalar relativistic corrections, and here we conservatively allow for $\pm 2 \mathrm{~kJ} \mathrm{~mol}^{-1}$ error limits.

Dunning et al. [24] recommend their cc$\mathrm{pV}(n+\mathrm{d}) \mathrm{Z}$ basis sets over cc-pVnZ for improved convergence in species with second-row atoms. This is borne out in the present reactions. Initial attempts to derive CBS limits with the augcc-pVnZ basis sets led to CBS limits for $\Delta_{\mathrm{f}} H_{0}$ from reactions (1)-(3) of 268, 261 and $279 \mathrm{~kJ} \mathrm{~mol}^{-1}$, respectively. The convergence was slower than with the extra $\mathrm{d}$ functions, and as a consequence, the CBS values are more scattered and not used in this work. Our value for $\Delta_{\mathrm{f}} H_{0}$ (NS) is consistent with the limited experimental data discussed in Section 1, and the calculation by Nguyen and coworkers [16], but has a much smaller uncertainty. Thermal corrections yield $H_{298}-H_{0}=$ $9.40 \mathrm{~kJ} \mathrm{~mol}^{-1}$ and hence $\Delta_{\mathrm{f}} H_{298}(\mathrm{NS})=278.0$ $\mathrm{kJ} \mathrm{mol}^{-1}$.

The implied N-S bond dissociation enthalpies at 0 and $298 \mathrm{~K}$, respectively, are 468.2 and $471.7 \mathrm{~kJ} \mathrm{~mol}^{-1}$. The former value compares well with O'Hare's [12] value of $463 \pm 24 \mathrm{~kJ} \mathrm{~mol}^{-1}$, but with much smaller uncertainty. Gaydon [33] con- 
sidered linear Birge-Sponer extrapolations of 589 and $550 \mathrm{~kJ} \mathrm{~mol}^{-1}$, and recommended $482 \pm 68 \mathrm{~kJ}$ $\mathrm{mol}^{-1}$, which encompasses our calculated value.

$D_{0}(\mathrm{~S}-\mathrm{O})$ is $516.5 \mathrm{~kJ} \mathrm{~mol}^{-1}[14]$, so it may be seen that sulfur bonding to nitrogen is somewhat weaker than to oxygen. We might therefore expect NS to be labile in an oxidizing environment. Direct oxidation of $\mathrm{NH}_{2}$ by $\mathrm{O}_{2}$ is extremely slow [34], but in the presence of sulfur, $\mathrm{NH}_{2}$ may be converted to NS which could provide an alternative route to $\mathrm{NO}_{x}$. Our thermochemistry together with JANAF data [14] indicate that

$\mathrm{NH}_{2}+\mathrm{SO} \rightarrow \mathrm{NS}+\mathrm{H}_{2} \mathrm{O}$

is exothermic by $159 \mathrm{~kJ} \mathrm{~mol}^{-1}$ and is therefore feasible. Schofield considered

$\mathrm{NS}+\mathrm{OH} \rightarrow \mathrm{NO}+\mathrm{SH}$

to be a potential fate of $\mathrm{NS}$ and source of $\mathrm{NO}_{x}$ [35], and the present thermochemistry shows that reaction (6) is exothermic by $87 \mathrm{~kJ} \mathrm{~mol}^{-1}$ at $298 \mathrm{~K}$.

\section{Conclusions}

Coupled-cluster calculations, together with extrapolation to the complete basis set limit and corrections for anharmonic zero-point energy, relativistic terms and core-valence electron correlation, yield an enthalpy of formation of NS that should be reliable to within about $2 \mathrm{~kJ} \mathrm{~mol}^{-1}$.

\section{Acknowledgements}

We thank Dr. Kirk Peterson for providing his cc-pwCnV basis sets. This work was supported by the National Science Foundation (Grant CTS0113606), the Robert A. Welch Foundation (Grant B-1174) and the UNT Faculty Research Fund, and the calculations were performed on the National Center for Supercomputing Applications SGI/Cray Origin 2000 under Grant CHE000015N.

\section{References}

[1] J.O.L. Wendt, Combust. Flame 25 (1975) 355.

[2] J.O.L. Wendt, J.T. Morcomb, T.L. Corley, 17th Symp. (Int.) Combust. (1979) 671.
[3] J.O.L. Wendt, E.C. Wottan, T.L. Corley, Combust. Flame 49 (1983) 261.

[4] T.L. Corley, J.O.L. Wendt, Combust. Flame 58 (1984) 141.

[5] S.I. Tseregounis, O.I. Smith, Combust. Sci. Technol. 30 (1983) 231.

[6] A.T. Chen, P.C. Malte, M.M. Thornton, 20th Symp. (Int.) Combust. (1984) 769.

[7] L.D. Pfefferle, S.W. Churchill, Ind. Eng. Chem. Res. 28 (1989) 1004.

[8] W. Nimmo, E. Hampartsoumian, K.J. Hughes, A.S. Tomlin, Proc. Comb. Inst. 27 (1998) 1419.

[9] J.B. Jeffries, D.R. Crosley, Combust. Flame 64 (1986) 55.

[10] M.A. Blitz, M.J. Pilling, Sulphur Centered Reactions of Importance in Combustion, 16th Int. Symp. Gas Kinetics, 2000, paper C1.

[11] K.P. Huber, G. Herzberg, Constants of Diatomic Molecules, Van Nostrand Reinhold, New York, 1979.

[12] P.G. O’Hare, J. Chem. Phys. 52 (1970) 2992.

[13] L.V. Gurvich, I.V. Veyts, C.B. Alcock, 4th, Hemisphere, New York, 1989.

[14] M.W. Chase Jr. (Ed.), NIST-JANAF Thermochemical Tables, fourth ed., American Chemical Society and the American Institute of Physics, Woodbury, NY, 1998.

[15] G.C. Lie, S.D. Peyerimhoff, R.J. Buenker, J. Chem. Phys. 82 (1985) 2672.

[16] M.T. Nguyen, L.G. Vanquickenborne, R. Flammang, J. Chem. Phys. 101 (1994) 4885.

[17] D. Feller, K.A. Peterson, J. Chem. Phys. 108 (1998) 154.

[18] K.A. Peterson, T.H. Dunning Jr., J. Chem. Phys. 106 (1997) 4119.

[19] K.L. Bak, P. Jorgensen, J. Olsen, T. Helgaker, W. Klopper, J. Chem. Phys. 112 (2000) 9229.

[20] L.R. Peebles, P. Marshall, J. Chem. Phys. 117 (2002) 3132.

[21] H.-J. Werner, P.J. Knowles, R.D. Amos, A. Bernhardsson, A. Berning, P. Celani, D.L. Cooper, M.J.O. Deegan, A.J. Dobbyn, F. Eckert, C. Hampel, G. Hetzer, T. Korona, R. Lindh, A.W. Lloyd, S.J. McNicholas, F.R. Manby, W. Meyer, M.E. Mura, A. Nicklass, P. Palmieri, R. Pitzer, G. Rauhut, M. Schutz, H. Stoll, A.J. Stone, R. Tarroni, T. Thorsteinsson, Molpro Quantum Chemistry Package 2000.1, 2000.

[22] T.H. Dunning Jr., J. Chem. Phys. 90 (1989) 1007.

[23] D.E. Woon, T.H. Dunning Jr., J. Chem. Phys. 98 (1993) 1358.

[24] T.H. Dunning Jr., K.A. Peterson, A.K. Wilson, J. Chem. Phys. 114 (2001) 9244.

[25] K.A. Peterson, cc-pwCVxZ basis sets. Personal communication, 2000.

[26] R.L. Martin, J. Phys. Chem. 87 (1983) 750.

[27] D.G. Truhlar, A.D. Isaacson, J. Chem. Phys. 94 (1991) 357.

[28] A.D. Isaacson, X.-G. Zhang, Theor. Chim. Acta 74 (1988) 493.

[29] J.M.L. Martin, T.J. Lee, Chem. Phys. Lett. 258 (1996) 136.

[30] J.M.L. Martin, Chem. Phys. Lett. 259 (1996) 679.

[31] A.K. Wilson, T.H. Dunning Jr., J. Chem. Phys. 106 (1997) 8718. 
[32] P. Hassanzadeh, K.K. Irikura, J. Phys. Chem. A 101 (1997) 1580.

[33] A.G. Gaydon, Dissociation Energies and Spectra of Diatomic Molecules, third ed., Chapman \& Hall, London, 1968.
[34] A.M. Dean, J.W. Bozzelli, in: W.C. Gardiner Jr. (Ed.), Gas-Phase Combustion Chemistry, Springer-Verlag, New York, 2000, Chapter 2.

[35] K. Schofield, Combust. Flame 124 (2001) 137. 